\title{
A PHILOSOPHY OF SEISMIC ZONING
}

\author{
G. A. Eilby*
}

Summary

Seismic zoning involves both economic questions, and questions of public safety. If it is accepted that the latter are more important, little justification for differing structural codes in different parts of New Zealand can be found. Consideration of the economic importance of the varying incidence of smaller earthquakes is hampered by the absence of properly costed engineering studies. Microzoning and the study of foundation conditions are of high importance。

The news that the New Zealand Standard Building Code is again under review prompts me to express a personal view on the seismic zone provisions it now contains. At the time these were introduced, their advocates stated that their purpose was to allow for regional differences in the risk of destructive earthquake. The view of New Zealand seismologists that these risks are substantially uniform over the country was rejected. Engineers who support the zoning provisions are now using very diff erent arguments in their favour; but even if we have reached the right result for the wrong reason, it is most desirable that the right reasons should be examined and set out when the code is revised.

As I understand the new argument, the provisions for zone $\mathrm{C}$ will prevent those structures that fail from failing in such a way that loss of life and serious injury result. The more stringent provisions for zones $A$ and $B$ have been added only to minimise the inconvience and economic loss involved in replacement, repair, and loss of occupancy. This seems to me in every way a reasonable and defensible attitude if complete protection everywhere is not possible, but it at once prompts secondary questions.

First, and most importantly, are the provisions of zone $C$ adequate? It would be impertinent for a seismologist to attempt to answer this, unless perhaps he had evidence that buildings of a kind he knows to have failed disastrously in the past could still be erected. This is not obviously the case, and he must therefore hold his peace and rely upon the vigilance and self-discipline of the engineering profession to ensure that new types of building are as safe as the old. If, however, engineers believe that in a destructive earthquake people in zone $C$ would be less safe than those in zone A, they are morally bound to increase the provision. The economic argument must not be allowed to cloud the issue of public safety.

* Geophysics Division, N.Z. Dept. of Scientific and Industrial Research
Those who consider it relevant frequently assert that anything approaching complete safety for the public is impossible. Here, I think, the engineer does himself less than justice. I know of no earthquake in which all structures have failed. Those that survive are those, broadly speaking, that an engineer would consider "good" buildings, quite apart from their anti-seismic properties. Since there are such buildings, and their builders have presumably been paid, the economic argument is obviously faulty and the public is entitled to demand that all buildings in zone $\mathrm{C}$ reach this standard。

Once engineers have established the proper minimum for zone $\mathrm{C}$, and all our citizens are safe, we can examine the economic consequences of the more frequent smaller earthquakes, and of the apparent variation in the frequency in their occurrence from district to district, and the cost of replacing or repairing these build. ings which, although they have not produced casualties, have failed in some way. We have also to consider whether these economic consequences are a private matter or one of public concern. If they are private, they have no place in legislation; but I believe them to be public. The owner of a damaged building will almost certainly suggest, if he does not demand that the government or some other public source indemnify him for his lack of foresight (or dare I say, for his gambling loss?). In these circumstances a realistic and compulsory insurance, with the premiums heavily loaded to dis courage the extremer sorts of speculation and folly, appears to be a more equitable way of ensuring that owners build sensibly than adding a factor to what is primarily a structural code to cover non-structural failures.

Accepting that some features of building construction should or may be varied with the Erequency of earthquake occurrence, it becomes important to determine the range of the variation in economic terms. If the difference in cost between the maximum and minimum protection is very small, there is no point in subdividing the requirements into a number of only slightly differing classes. Here the engineering profession is guilty of concealment. No engineer I have asked (and I have asked many of those most directly concerned) has ever put a believable figure on this difference, and $I$ am far from sure that it is significant in terms of the total cost of the structure.

Not all questions about zoning should be directed at the engineer. There are some the seismologist should answer and I am not sure that he can always do so. Let me begin with one of the simpler ones. It has long been known that the degree of shaking experienced at 
a given distance from an earthquake origin depends greatly upon the nature of the ground. A classical estimate of the difference between the best and worst foundations is 4 degrees of the Mercalli scale. If we look at the isoseismals of the Napier or Murchison earthquake, we find that it would be necessary to travel some $200 \mathrm{~km}$ to produce a comparable change in intensity by moving our position. On this ground alone, the seismologist is justified in insisting that in a small country microzoning based on foundation is a much higher priority than the kind of zoning used in the present code, in which zone boundaries come within a few miles of major centres of population.

The question of establishing differences in the frequency of occurrence of shocks of moderate size is more complex than it appears at first. If we are dealing with seismic systems of provincial size, a simple count of say, the number of shocks above magnitude 4 in a unit area per decade, counted over a period of about 20 years, gives a reasonable basis of comparison. We can, for example, be confident that the activity in Fiordland is about double that in the Main Seismic Region near Cook Strait. When we look at smaller areas - say, the Hutt Valley and a comparable area near Masterton, it will depend very much which 20 years we select. Similarly, if we take even less active parts of the country, like the Northland Peninsula or the Lake Coleridge district, we find that periods when the seismicity is comparable with that in parts of the Main and Fiordland Regions alternate with quiescent periods that may last for several years, or even for many decades. It is well established that the danger of major earth quake is present in these areas. The temporary absence of minor activity, even if it is pro1 onged, must not allow this to be forgotten. The seismologist is very interested in the pattern of behaviour of the minor shocks. An estimate of the economic importance of the variations might well influence the priority he gives to studies in this field.

I hope that the reasons for my own order of priorities are clear. Public safety comes first, the protection of investment later. structural zoning is a question of safety, and my advice is simple and definite. In New

Zealand the risk is everywhere, and all must be protected. The economic priorities are not so clear, not because of seismological uncertainty, but because the engineering costs have not been estimated, or if they have, they have not reached the seismologist. Microzoning and the study of foundation characteristics are almost certainly more important economically than the variations in the frequency of earthquake occurrence, but in the long run the occurrence patterns are more likely to shed light on the most fundamental questions of a11: just what is an earthquake, what areas are likely to be affected, and what intensities will be reached? Engineers can be assured that seismologists have not forgotten them. 